\title{
Statins, indication creep and risks for children and youth
}

$\mathrm{M}$ ore than half of the drugs given to children and youth in hospital are used off label. Although therapy given to adults is usually guided by evidence, the evidence for the use of these drugs in children is often scant or nonexistent. Physicians are thus faced with a dilemma: treat without evidence and risk serious adverse outcomes or deny use of drugs that may save a life or enhance its quality.

This problem continues despite many years of calls for more safety and efficacy trials that include children. There are many examples of the death of a child because a drug did not perform the same way it does in an adult. Children are not just small adults, especially in terms of drug effects. Pharmacokinetics, pharmacodynamics, efficacy and adverse outcomes can differ markedly.

Recent recommendations from the Committee on Nutrition of the American Academy of Pediatrics remind us that the problem of "age indication creep" in children is not restricted to drugs used in hospital. ${ }^{1}$ The American Academy of Pediatrics recommends consideration of drug therapy for dyslipidemia in patients as young as 8 years old who meet specified criteria, including familial and nonfamilial hypercholesterolemia. ${ }^{1}$ Statins are among the recommended medications. The US Food and Drug Administration has approved the use of statins in children for treatment of familial hypercholesterolemia but not for treatment of other dyslipidemias.

Direct evidence for the safety and efficacy of statins in children and youth is limited. Approval from the Food and Drug Administration was based on data extrapolated from adult studies and on short-term studies of statin use in children and adolescents with familial hypercholesterolemia. Eleven studies involving children (virtually all with familial hypercholesterolemia), which included a total of 665 patients receiving statins and 331 controls, reported an average lowdensity lipoprotein decrease of 32\% (range 17\%-45\%). ${ }^{2}$ Only 1 study followed patients for more than 1 year. There are no studies that have evaluated the long-term clinical benefit, such as decrease in myocardial infarction decades later. Guidelines for long-term use of statins in children and youth are therefore based on no evidence of either efficacy or safety.

We are just beginning to understand in adults how the risk of serious adverse outcomes, such as rhabdomyolysis, with statin use is determined by variability in the expression and activity of transporter systems. The ontogeny and expression of many of these key systems is not yet understood in childhood. This adds to the uncertainty about the long-term safety. Moreover, the observation that certain subpopulations of adults may be at high risk for statin-related toxicity raises further concerns about potential toxicity in children. Also, some statins, including simvastatin and lovastatin, can cross the blood-brain barrier. This is concerning because lipids have a key role in normal brain development, and neurodevelopment and integration of signal processing are intense during adoles- cence and young adulthood. ${ }^{3}$ Extrapolation from safety data derived from adults, for whom brain development is long completed, or from short-term trials involving adolescents is insufficient to address these concerns.

Prescribing statins to children and youth potentially commits them to decades of therapy. In the United States, there are incentives (e.g., longer patent protection) for pharmaceutical companies to carry out randomized trials involving children and youth for new medications aimed primarily at the adult market but with the potential for pediatric use. Unfortunately, there is no incentive to perform the extended postlicensure cohort studies needed to determine efficacy and safety of long-term therapies. Yet without such studies, we risk repeating the fiasco of clinical use based upon "good extrapolated science" from short-term evidence, such as occurred with diethylstilbestrol.

Drug regulatory agencies must have the ability to mandate active surveillance and assessment programs for children and youth on long-term use of medications such as statins. Underinvestment in this area puts our children and youth at risk for unknown sequelae. However, optimizing health outcomes for this age group can potentially reap huge public health benefits, given their life trajectory. In the meantime, physicians treating children with dyslipidemias who do not have familial hypercholesterolemia should focus first on ensuring that alternatives to drug therapy, such as diet, exercise and other lifestyle factors, have been fully and repeatedly addressed. The beguiling ease of prescribing a pill may be an illconsidered decision to commit our youngest patients indefinitely to an unknown balance between benefit and harm.

\section{Noni MacDonald MD MSc \\ Section Editor, Public Health \\ Matthew B. Stanbrook MD PhD \\ Deputy Editor, Scientific \\ CMAJ \\ Michael J. Rieder MD PhD \\ CIHR-GSK Chair in Paediatric Clinical Pharmacology \\ University of Western Ontario \\ London, Ont. \\ With the Editorial-Writing Team (Paul C. Hébert MD MHSc, Barbara Sibbald BJ, Ken Flegel MDCM MSc, and Amir Attaran LLB DPhil)}

Competing interests: See www.cmaj.ca/misc/edboard.shtml for the EditorialWriting Team's statements. None declared for Michael J. Rieder.

\section{REFERENCES}

1. Daniels SR, Greer FR, the Committee on Nutrition. Lipid screening and cardiovascular health in childhood. Pediatrics 2008;122:198-208.

2. Tapia Ceballos L, Picazo Angelina B, Ruiz Garcia C. Uso de estatinas durante la infancia. An Pediatr (Barc) 2008;68:385-92.

3. Lebel C, Walker L, Leemans A, et al. Microstructural maturation of the human brain from childhood to adulthood. Neuroimage 2008;40:1044-55. 